\title{
Numerical analysis of the injection law influence on NOx emissions for a compression ignited engine
}

\author{
Dan Moldovanu ${ }^{1, *}$, Florin Mariașiu ${ }^{1}$ \\ ${ }^{1}$ Technical University of Cluj-Napoca, Cluj-Napoca, Romania
}

\begin{abstract}
Under the present conditions, where sustained efforts are being made by researchers and automotive industry developers to reduce toxic gases (and fitting them into existing pollution standards), research is required to define the possible directions to be followed for this purpose. One of these directions is also presented in this paper.The paper presents research done by using numerical analysis of the influence of the injection law on NOx emission on compression ignited engines. Instead of a normal injection law, a particular injection law was considered to reduce the effect of the cavity on the fuel flow inside the injector in order to achieve a more homogeneous fuel jet exit at the injector.It is noted that there are NOx emission reductions of up to $20 \%$ (obtained at 760 degrees CA) compared to the initial injection law, which confirms the need to continue studying the presented research topic. There are also differences in the formation and development of NOx emission zones within the combustion chamber (the volume and positioning of the contact surface towards the walls of the combustion chamber)..
\end{abstract}

\section{Introduction}

Considering the stringent European norms regarding emissions, there are many articles and dedicated journals on emission reduction.

Nehmer and Reitz have written a manuscript regarding the measurement of the effect of injection rate and split injections on diesel engine Soot and NOx emissions. The study on a heavy-duty diesel engine was made to understand how rate-shaped and split injection can affect both the soot and the NOx emissions. The provided results shown that split injections allowed peak pressures to be reduced by more than $45 \%$ and have a significant effect on the overall rate of pressure rise. The authors indicated that pulsed injection may provide a means to reduce particulate emissions and allow for reduced NOx from controlled pressure rise [1].Patterson et.al. also investigated a way of reducing the Soot and NOx emissions by modelling the effects of fuel injection characteristics, using the three-dimensional KIVA code. Given that the Soot and NOx emissions are very sensitive to factors that influence the chamber gas temperatures, the results show that the combustion is controlled by the details of the spray model. Furthermore, computations have showed that soot and NOx emissions increase at low injection pressures [2].

Kook et.al. investigated the influence of charge dilution and injection timing on low-temperature diesel combustion and emissions. They have emphasized that by lowering the flame temperature and by influencing the local charge equivalence ratio through intake charge dilution, this offers the potential of avoiding both soot and NOx formation. The conclusion they highlighted was that although the ignition delay increased with high dilution and early injection, the heat release analysis indicated that a large portion of the combustion and emissions formation processes was still dominated by the mixing-controlled phase [3].

Many papers were concentrated on reducing the soot and NOx emissions using multiple injections. Although each paper has approached the problem from a different point of view, all the authors have reached the conclusion that multiple injections indeed lead to a reduced quantity of emissions [4]-[7].

Payri et.al. investigated the influence of post-injection pattern on performance, soot and NOx emissions in a HD diesel engine. During the tests, EGR (exhaust gas recirculation) was introduced to reduce NOx emissions to a given value, and then different post-injection patterns were produced.

The final results obtained allowed the authors to discern the effects produced by the different postinjection patterns and to assess their potential for Soot emissions reduction, keeping NOx emissions and fuel consumption at the original values [8].

Many authors tend to go towards renewable energy, seeing how badly the emissions from presently used energy fuels have increased and how harmful they are. Others on the other hand chose to concentrate on making our present systems and fuels better.

The authors either choose experimental investigations to control the emissions, try to better understand the fuel properties and composition to lower the NOx emissions, or they even concentrate more in detail regarding the emissions from DME (Dimethyl Esther) combustion in

\footnotetext{
*Corresponding author: dan.moldovnau@auto.utcluj.ro
} 
diesel engines and their implications on meeting future emission norms [9]-[12].

In order to further investigate the properties and influences of the injection law influence on NOx emissions for a compression ignited engine, the authors proposed a study using AVL FIRE and AVL FIRE ESE DIESEL (by AVL GmbH), presented in the following chapter.

\section{Methodology}

The methodology used for the current simulation starts with the correct input data. The simulation mesh and boundary were made using FIRE ESE DIESEL, where the general data were introduced (presented in Table 1), the piston was created from a template piston shape, after measuring the real piston section. The introduced data for the piston geometry parameters are presented in Fig. 1. After introducing the geometry of the piston, it is important to check that the actual compression ratio is still close to the imposed compression ratio.

Table 1.General data for the simulated engine.

\begin{tabular}{|c|c|}
\hline Paramenter & Dimension \\
\hline Bore & $70 \mathrm{~mm}$ \\
\hline Compression ratio & 21 \\
\hline Crank radius & $37.5 \mathrm{~mm}$ \\
\hline $\begin{array}{c}\text { Connecting rod } \\
\text { length }\end{array}$ & $80 \mathrm{~mm}$ \\
\hline Piston offset & 0 \\
\hline
\end{tabular}

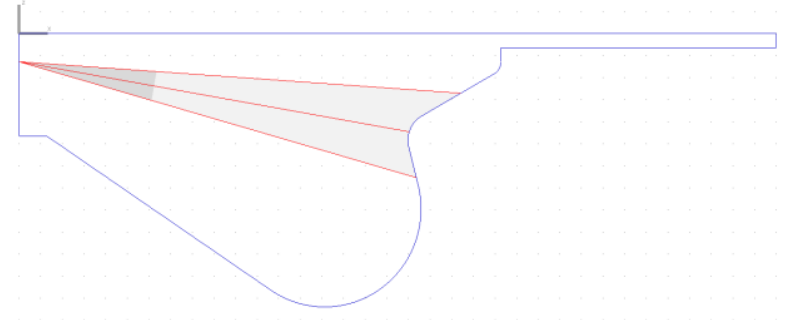

Fig. 1. Piston geometry parameters.

The next step was to generate the $3 \mathrm{D}$ meshes and check all the moving meshes for triangle faces that can diverge the simulation. The final mesh and all the selections are presented in Fig. 2.

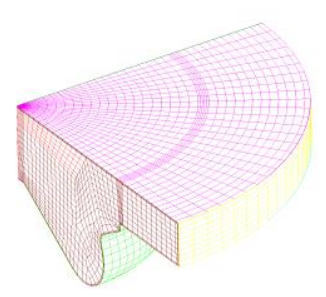

Fig. 2. Final mesh and selections

The important selections that were made, are: piston bowl, cylinder liner, cylinder head, and the symmetry selection.

After having the moving mesh, the Solver Steering File was addressed. Starting with Crank-angle (CA) run mode (from 540 to 800 deg CA), with module activation for species transport, combustion (the module that simulates the turbulent combustion of inhomogeneous mixtures of hydrocarbon fuel, air and exhaust gas.), spray (the module that simulates sprays based on the Discrete Droplet Method (DDM), which represents a spray as a statistical sample of discrete parcels.) and emissions.

The boundary conditions that were introduced are: Mesh movement for the piston selection and an imposed temperature of $575.15 \mathrm{~K}$, wall boundary condition for the cylinder liner, with a temperature of $475.15 \mathrm{~K}$, a simple symmetry boundary for the symmetry selection, and a wall boundary condition for the cylinder head, with a temperature of $550.15 \mathrm{~K}$ presented in Fig. 3.

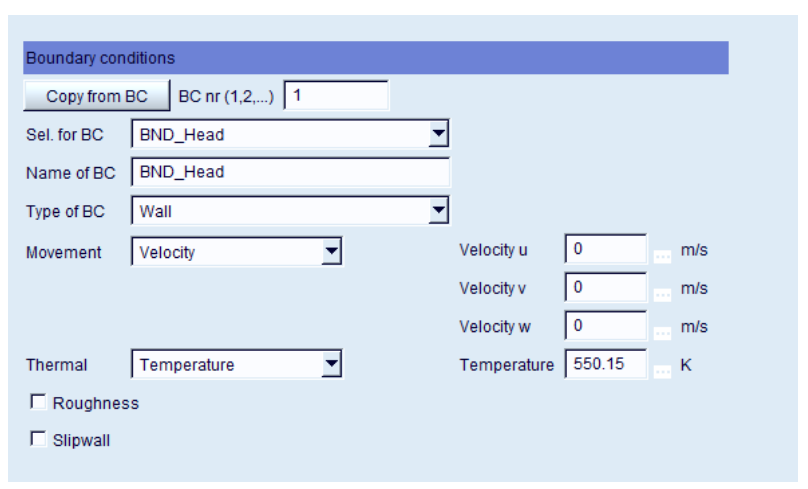

Fig. 3. Boundary conditions for the cylinder head

For the liquid properties, DIESEL was selected and a set temperature of $330.15 \mathrm{~K}$.

The injected mass per cycle was $10 \mathrm{mg}$. The start of injection angle (SOI) was $719 \mathrm{deg} \mathrm{CA}$, and the end of injection angle (EOI) was 734 deg CA (Fig. 4).

The injection law was changed, by modifying the injection rate, but the injected quantity was kept at $10 \mathrm{mg}$. 


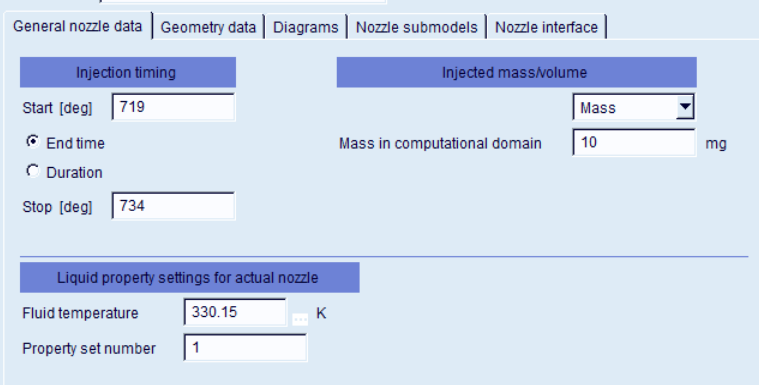

Fig. 4. Injection timing and quantity

The main idea of the paper, was to change the opening of the injector in steps, so that the same quantity of fuel is introduced, but with different flow velocities. The injection rates for the normal and step injection are presented in Fig. 5 and 6.

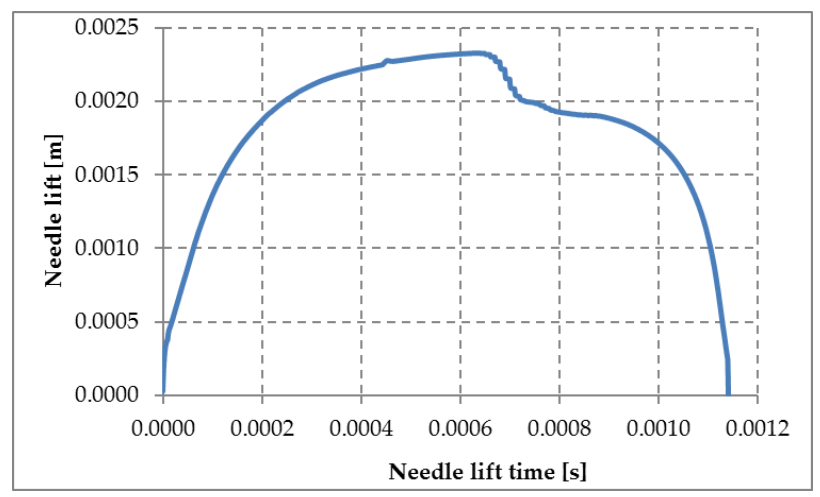

Fig.5.Standard injection rate

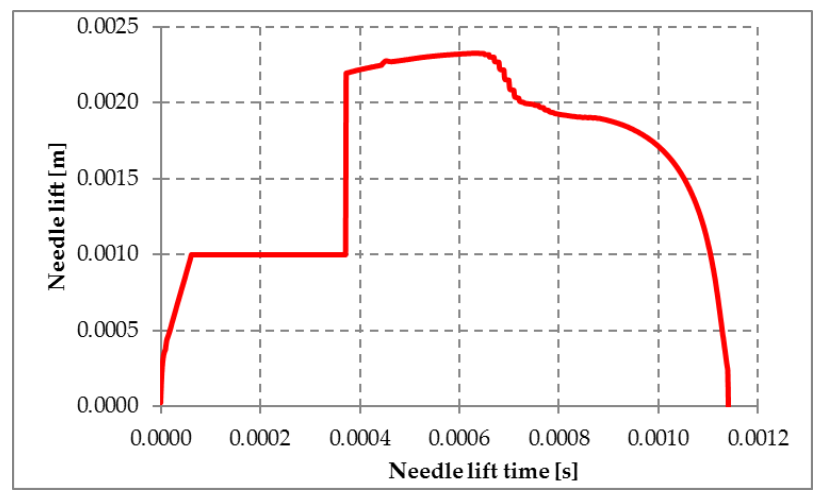

Fig. 6. Step injection rate

In AVL FIRE the k-zeta-f model was activated, with the aim to improve numerical stability by solving the transport equation for the velocity scale ratio $\zeta=\overline{\vartheta^{2}} / k$. The eddy-viscosity is obtained from (Eq. 1):

$$
v_{t}=C_{\mu} \zeta \frac{k^{2}}{\varepsilon}
$$

The turbulent time scale $\mathrm{T}$ and length scale $\mathrm{L}$ are given by (Eq.2 and 3):

$$
\begin{gathered}
T=\max \left(\min \left(\frac{k}{\varepsilon}, \frac{a}{\sqrt{6} C_{\mu}|S| \zeta}\right), C_{T}\left(\frac{v}{s}\right)^{\frac{1}{2}}\right) \\
T=C_{L} \max \left(\min \left(\frac{k^{\frac{3}{2}}}{s}, \frac{k^{\frac{1}{2}}}{\sqrt{6} C_{\mu}|S| \zeta}\right), C_{\eta} \frac{v^{\frac{3}{4}}}{s^{\frac{1}{4}}}\right)
\end{gathered}
$$

, where $\mathrm{C}_{\mu}=0.22, \mathrm{C}_{\mathrm{T}}=6, \mathrm{C}_{\mathrm{L}}=0.36$ and $\mathrm{C}_{\eta}=85$.
After the simulation was done for the standard injection rate, the step injection simulation was made and the results in NOx formation and

\section{Results}

To monitor the input of the simulation, the combustion equivalence ratio was monitored. The results are presented in Fig. 7, 9 and 11 for the standard injection at 720, 724 and 730 deg CA and in Fig. 8, 10 and 12 for step injection, at the same CA.

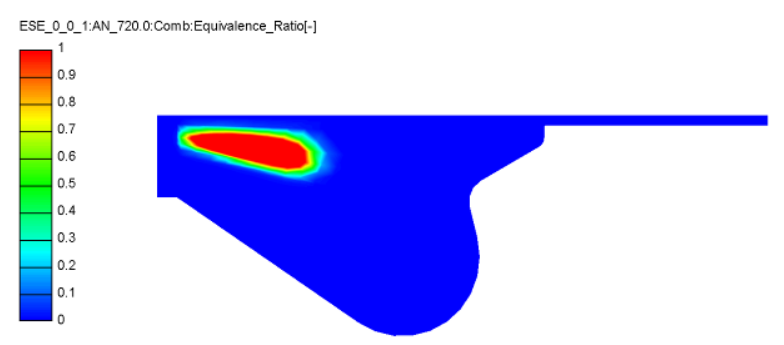

Fig. 7. Equivalence ratio for standard injection at $720 \mathrm{deg}$ $\mathrm{CA}$

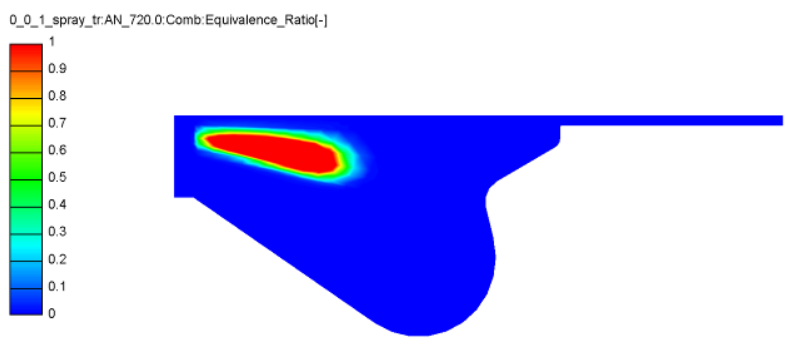

Fig. 8. Equivalence ratio for step injection at $720 \mathrm{deg} C A$

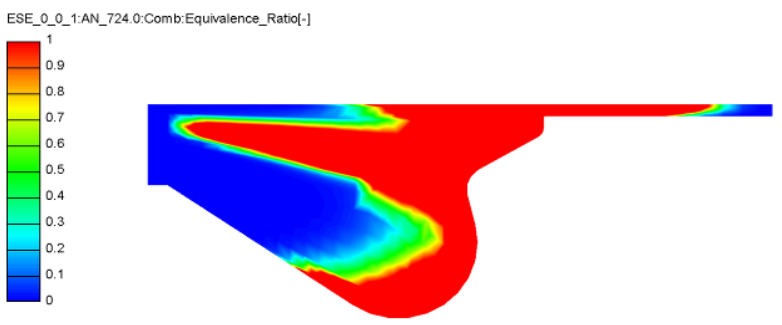

Fig. 9. Equivalence ratio for standard injection at $724 \mathrm{deg}$ CA

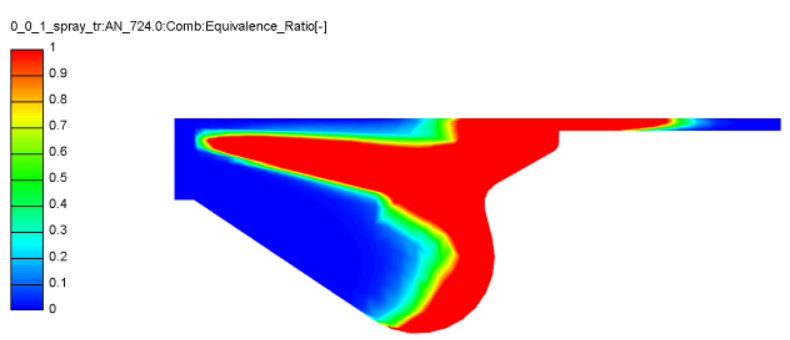

Fig. 10. Equivalence ratio for step injection at $724 \mathrm{deg} C A$ 


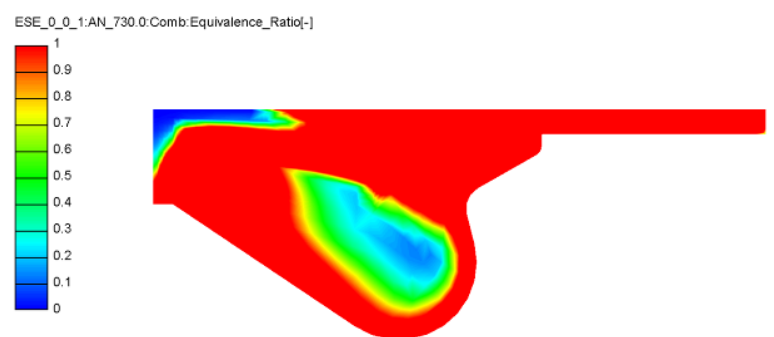

Fig. 10. Equivalence ratio for standard injection at $724 \mathrm{deg}$ CA

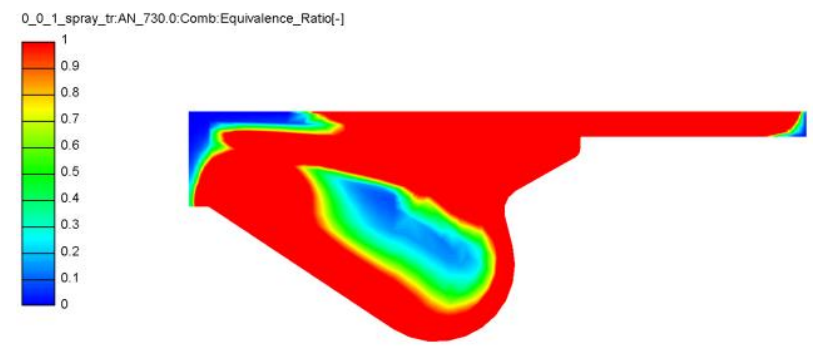

Fig. 11. Equivalence ratio for step injection at $724 \mathrm{deg} C A$

From Fig. 7-11 the observation is that the penetration of the standard injection is larger than the step injection, at the same timing, and because the quantity of the injected fuel is the same, the emissions will be different.

In order to monitor the NOx emissions, sections were made at 745,760 and $780 \mathrm{deg}$ CA respectively (presented in Fig. 12-17) and even though the maximal values were different, the scales were chosen the same so that colours mean the same NOx concentration in all sections.

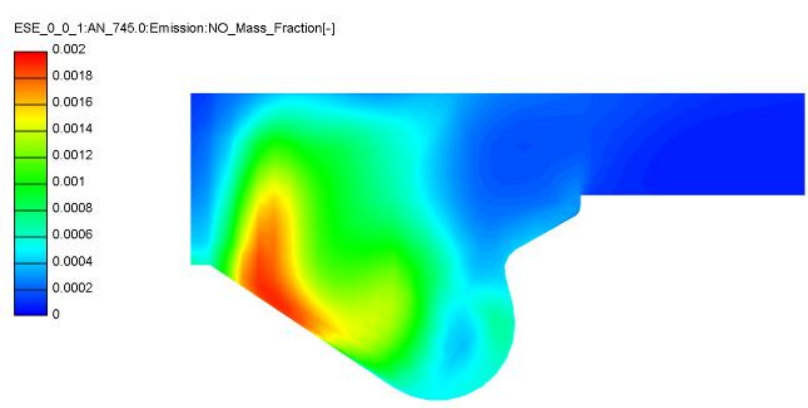

Fig. 12. NOx for standard injection at $745 \mathrm{deg} C A$

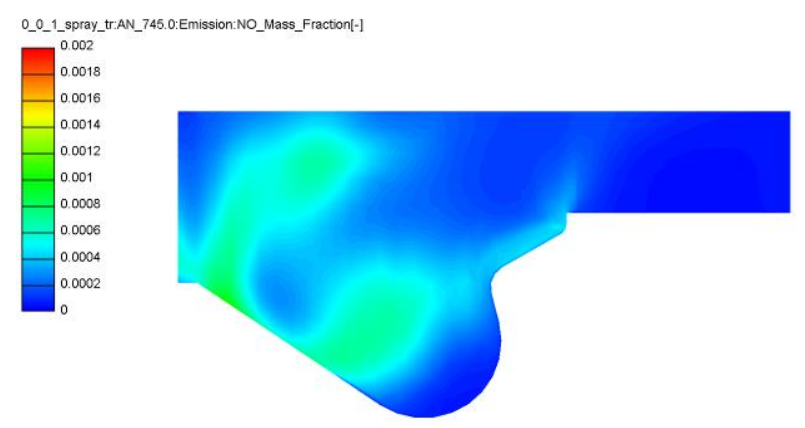

Fig. 13. NOx for step injection at $745 \mathrm{deg} C A$

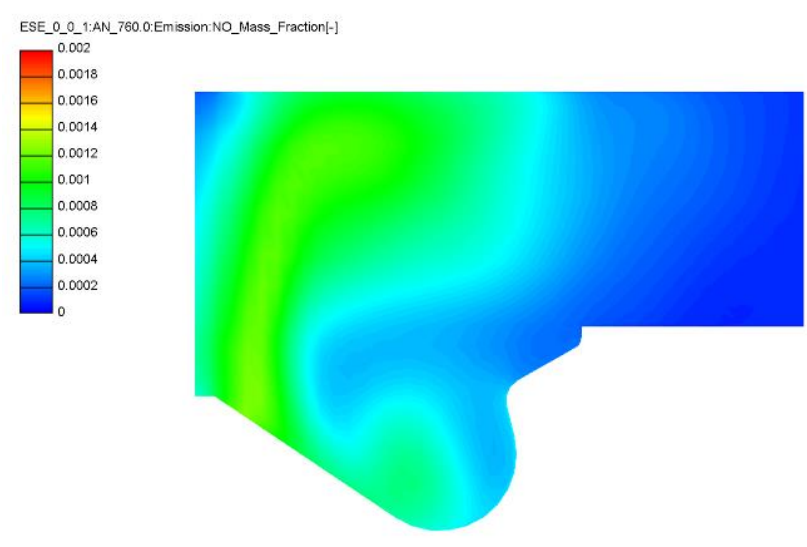

Fig. 14. NOx for standard injection at $760 \mathrm{deg} C A$

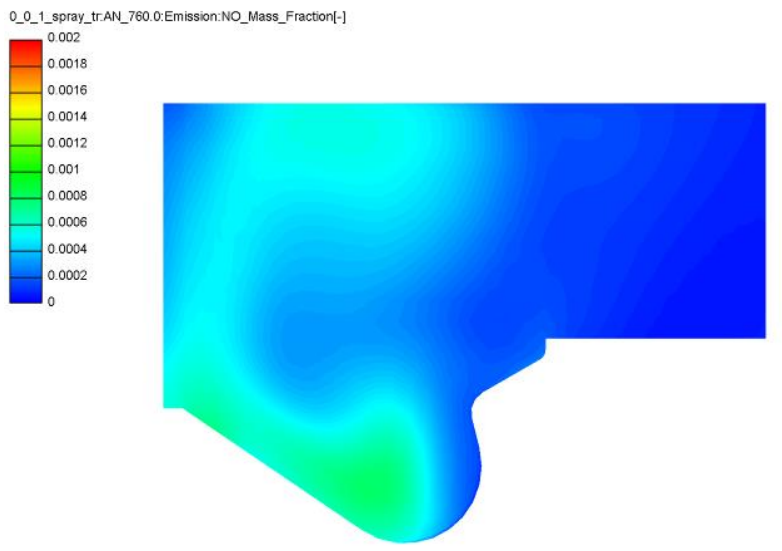

Fig. 15. NOx for step injection at $760 \mathrm{deg} C A$

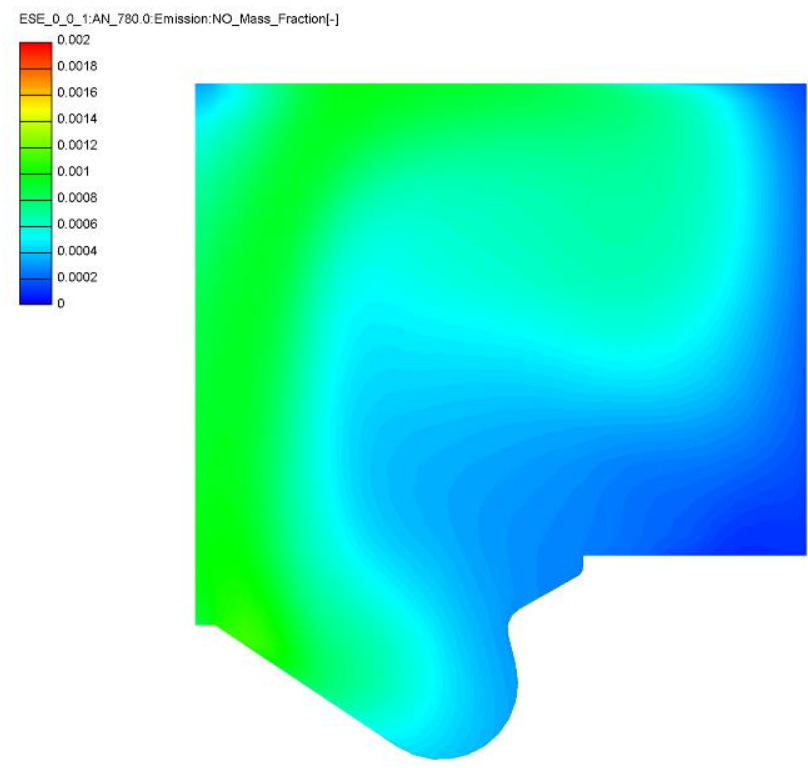

Fig. 16. NOx for standard injection at $780 \mathrm{deg} C A$ 


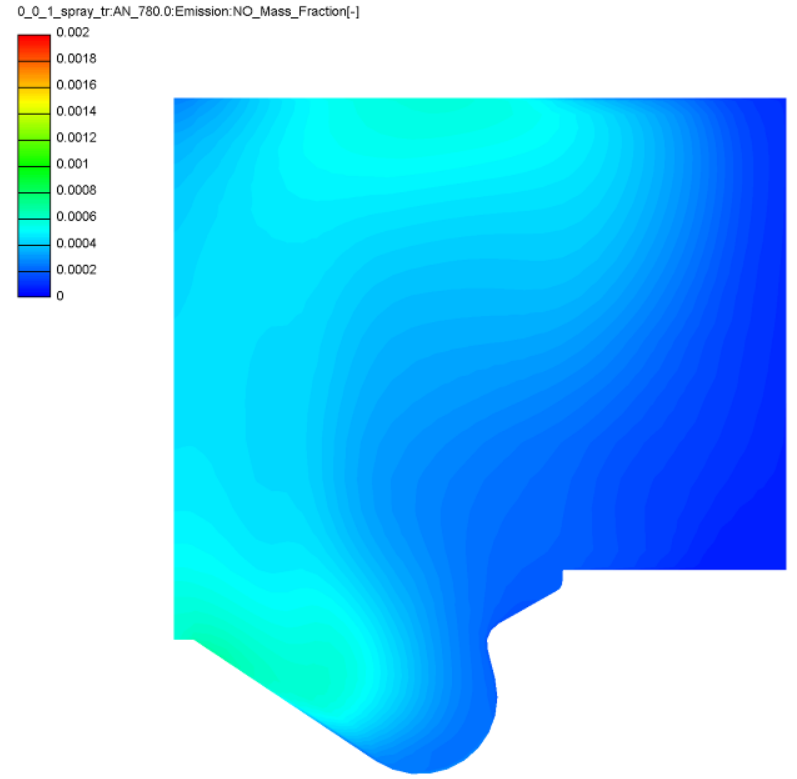

Fig. 17. NOx for step injection at $780 \mathrm{deg} \mathrm{CA}$

The results for Max NOx on the entire mesh and Average NOx value area weighted for both standard injection and step injection were extracted for different CA and are presented in Tables 2 and 3 and are presented in Fig. 18 and 19.

Table 2. Max NOx on the entire mesh and Average NOx value area weighted for standard injection.

\begin{tabular}{|l|c|c|c|c|c|}
\hline CA [deg] & 730 & 745 & 760 & 780 & 800 \\
\hline $\begin{array}{l}\text { Max NOx } \\
\text { on entire } \\
\text { mesh [-] }\end{array}$ & $\begin{array}{c}2.31 \mathrm{E}- \\
03\end{array}$ & $\begin{array}{c}1.99 \mathrm{E}- \\
03\end{array}$ & $\begin{array}{c}1.32 \mathrm{E}- \\
03\end{array}$ & $\begin{array}{c}1.15 \mathrm{E}- \\
03\end{array}$ & $\begin{array}{c}1.06 \mathrm{E} \\
-03\end{array}$ \\
\hline $\begin{array}{l}\text { Average } \\
\text { NOx } \\
\text { value area } \\
\text { weighted } \\
{[-]}\end{array}$ & $\begin{array}{c}7.54 \mathrm{E}- \\
05\end{array}$ & $\begin{array}{c}5.95 \mathrm{E}- \\
04\end{array}$ & $\begin{array}{c}5.36 \mathrm{E}- \\
04\end{array}$ & $\begin{array}{c}5.63 \mathrm{E}- \\
04\end{array}$ & $\begin{array}{c}5.07 \mathrm{E} \\
-04\end{array}$ \\
\hline
\end{tabular}

Table 3. Max NOx on the entire mesh and Average NOx value area weighted for step injection.

\begin{tabular}{|l|c|c|c|c|c|}
\hline CA [deg] & 730 & 745 & 760 & 780 & 800 \\
\hline $\begin{array}{l}\text { Max NOx } \\
\text { on entire } \\
\text { mesh [-] }\end{array}$ & $\begin{array}{c}1.50 \mathrm{E}- \\
03\end{array}$ & $\begin{array}{c}1.75 \mathrm{E}- \\
03\end{array}$ & $\begin{array}{c}8.90 \mathrm{E}- \\
04\end{array}$ & $\begin{array}{c}6.90 \mathrm{E}- \\
04\end{array}$ & $\begin{array}{c}6.43 \mathrm{E} \\
-04\end{array}$ \\
\hline $\begin{array}{l}\text { Average } \\
\text { NOx } \\
\text { value area } \\
\text { weighted } \\
{[-]}\end{array}$ & $\begin{array}{c}1.40 \mathrm{E}- \\
05\end{array}$ & $\begin{array}{c}3.05 \mathrm{E}- \\
04\end{array}$ & $\begin{array}{c}3.25 \mathrm{E}- \\
04\end{array}$ & $\begin{array}{c}3.45 \mathrm{E}- \\
04\end{array}$ & $\begin{array}{c}3.40 \mathrm{E} \\
-04\end{array}$ \\
\hline
\end{tabular}

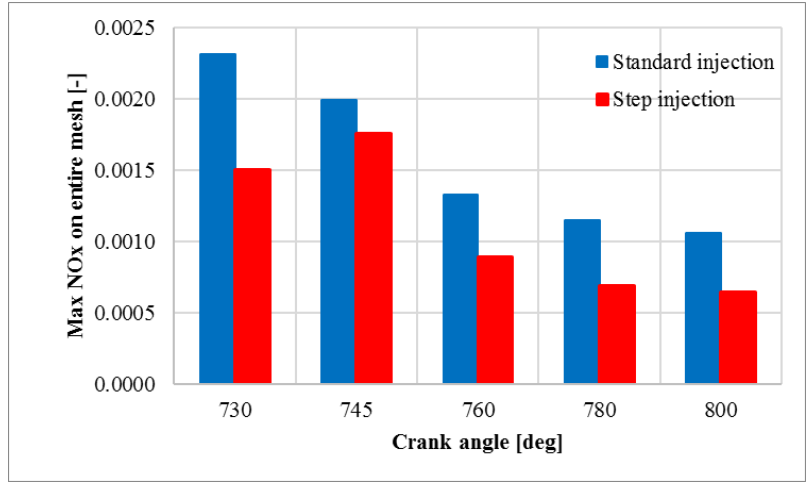

Fig. 18. Variation of Max NOx on the entire mesh

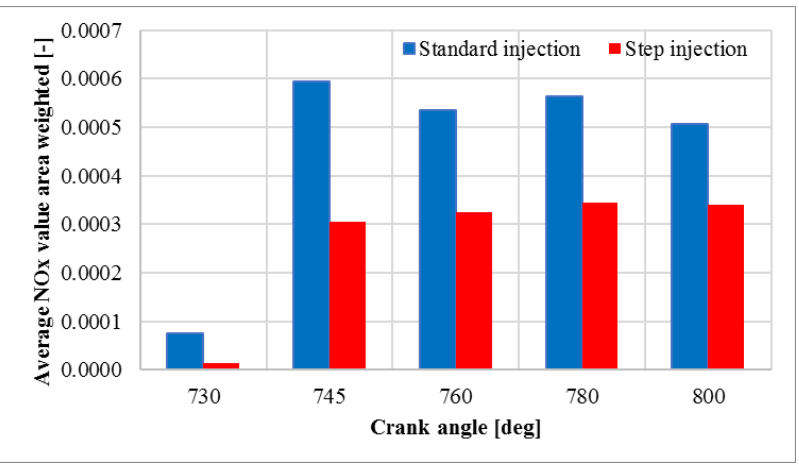

Fig. 19. Variation of Average NOx value area-weighted

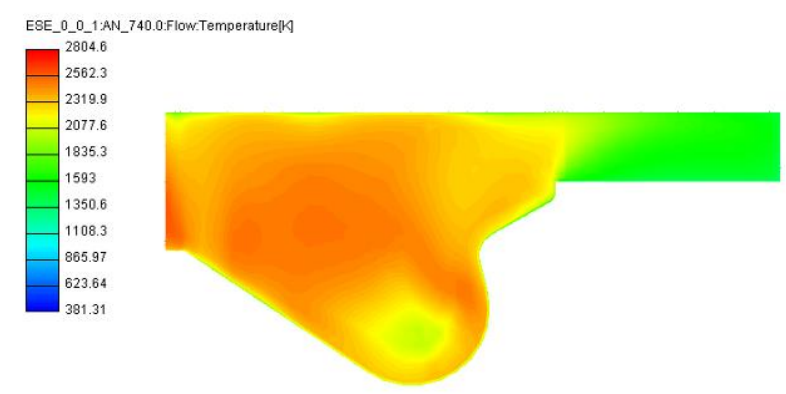

Fig. 20. Variation of the temperature inside the combustion chamber at $740 \mathrm{deg}$ CA for standard injection

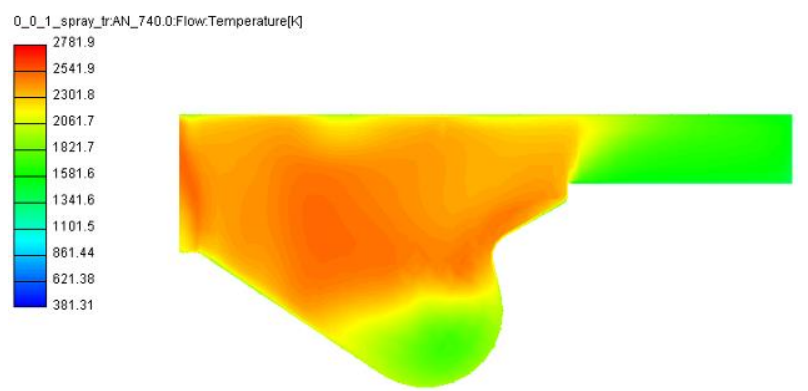

Fig. 21. Variation of the temperature inside the combustion chamber at $740 \mathrm{deg}$ CA for step injection 


\section{Conclusions}

By analyzing the results, it can be seen from Fig. 1218 that the evolution of NOx formation is similar as shape and formation zone, but the values differ due to the different injection law.

Using the same scale and analysing the areas, it can be observed that for the standard injection the NOx emissions have a bigger area and value.

Graphs in Fig. 18 and 19 were made to underline the maximum NOx variation on the entire mesh and the Average area-weighted NOx value. For the standard injection the variation is clear, as the CA rises, the Max NOx concentration is lower for standard injection and also for the step injection (except $730 \mathrm{deg}$ CA), mainly because the temperature inside the cylinder is lower as the cycle evolves. The average area-weighted NOx value is low at $730 \mathrm{deg}$ CA, but at $745 \mathrm{deg}$ CA the values jump to 0.0006 (standard injection) and 0.0003 (step injection), the lower value is due to the lower temperature inside the combustion chamber for the step injection (like seen in Fig. 20 and 21).

\section{References}

1. D.A. Nehmer, R.D. Reitz, "Measurement of the effect of injection rate and split injections on diesel engine soot and NOx emissions". No. 940668. SAE Technical Paper, (1994).

2. M. A. Patterson, et al. "Modeling the effects of fuel injection characteristics on diesel engine soot and NOx emissions". No. 940523. SAE Technical Paper, (1994).

3. S. Kook, C. Bae, P.C. Miles, D. Choi, L.M. Pickett,"The influence of charge dilution and injection timing on low-temperature diesel combustion and emissions". No. 2005-01-3837. SAE Technical Paper, (2005).

4. D.T. Montgomery, and D.R. Rolf,"Six-mode cycle evaluation of the effect of EGR and multiple injections on particulate and NOx emissions from a DI diesel engine”. No. 960316. SAE Technical paper, (1996).

5. S.K. Chen, "Simultaneous reduction of NOx and particulate emissions by using multiple injections in a small diesel engine". No. 2000-01-3084. SAE Technical Paper, (2000).

6. Z. Han, , et al. "Mechanism of soot and NOx emission reduction using multiple-injection in a diesel engine." SAE transactions 105,837-852 (1996).

7. T.C. Tow, D.A. Pierpont, and D.R. Rolf,"Reducing particulate and NOx emissions by using multiple injections in a heavy duty DI diesel engine". No. 940897. SAE Technical Paper, (1994).

8. F Payri, J Benajes, J.V. Pastor, S Molina, "Influence of the post-injection pattern on performance, soot and NOx emissions in a HD diesel engine". No. 2002-010502. SAE Technical Paper, (2002).

9. D. Agarwal, S. Sinha, A.K. Agarwal, "Experimental investigation of control of NOx emissions in biodiesel-fueled compression ignition engine." Renewable energy 31.14,2356-2369 (2006).

10. A.K. Agarwal, et al. "Effect of fuel injection timing and pressure on combustion, emissions and performance characteristics of a single cylinder diesel engine." Fuel 111, 374-383 (2013).

11. G. Thomas, et al. "Emissions from DME combustion in diesel engines and their implications on meeting future emission norms: a review." Fuel processing technology 119,286-304, (2014).

12. K. Varatharajan, and M. Cheralathan. "Influence of fuel properties and composition on NOx emissions from biodiesel powered diesel engines: A review." Renewable and Sustainable Energy Reviews 16.63702-3710 (2012). 